CLINICAL STUDY

\title{
Repeated administration of ghrelin to patients with functional dyspepsia: its effects on food intake and appetite
}

\author{
Takashi Akamizu ${ }^{1}$, Hiroshi Iwakura ${ }^{1}$, Hiroyuki Ariyasu ${ }^{1}$, Hiroshi Hosoda ${ }^{1}$, Toshinori Murayama ${ }^{2}$, \\ Masayuki Yokode ${ }^{2}$, Satoshi Teramukai ${ }^{3}$, Hiroshi Seno ${ }^{4}$, Tsutomu Chiba ${ }^{4}$, Shunichi Noma ${ }^{5}$, Yoshikatsu Nakai ${ }^{6}$, \\ Mikihiko Fukunaga ${ }^{7}$, Yoshihide Nakai ${ }^{7}$, Kenji Kangawa ${ }^{1,8}$ and FD Clinical Study Team \\ ${ }^{1}$ Ghrelin Research Project, ${ }^{2}$ Department of Clinical Innovative Medicine, and ${ }^{3}$ Department of Clinical Trial Design and Management, Translational Research \\ Center, ${ }^{4}$ Department of Gastroenterolgy and Hepatology, and ${ }^{5}$ Department of Psychiatry, Kyoto University Hospital, and ${ }^{6}$ School of Health Sciences, \\ Faculty of Medicine, Kyoto University, Kyoto 606-8507, Japan, ${ }^{7}$ Department of Psychosomatic Medicine, Kansai Medical University, Moriguchi $570-$ \\ 8507, Japan and ${ }^{8}$ National Cardiovascular Center Research Institute, Osaka 565-8565, Japan \\ (Correspondence should be addressed to T Akamizu; Email: akamizu@kuhp.kyoto-u.ac.jp)
}

\begin{abstract}
Background: Ghrelin plays a major role in the regulation of food intake (FI), which makes it a strong candidate for the treatment of anorexia.

Objective: We attempted to evaluate the clinical response to repeated ghrelin administration in patients with anorexia caused by functional disorders, such as functional dyspepsia (FD).

Subjects and methods: Subjects included in this study were those who 1) were diagnosed with functional anorexia, including FD and other eating disorders with the exception of anorexia nervosa; 2) were lean (body mass index $(\mathrm{BMI})<22 \mathrm{~kg} / \mathrm{m}^{2}$ ); and 3) exhibited decreased FI. Subjects received an i.v. infusion of ghrelin $(3 \mu \mathrm{g} / \mathrm{kg}$ ) for $30 \mathrm{~min}$ twice a day (before breakfast and dinner) for 2 weeks. We investigated the effects of ghrelin administration on FI, appetite, hormones, and metabolic parameters.

Results: Six patients with FD were enrolled in this study. Ghrelin administration tended to increase daily FI in comparison with levels before and after completion of treatment, but this difference that was the primary endpoint of this study did not reach statistical significance $(P=0.084)$. Hunger sensation was significantly elevated at the end of drip infusion $(P<0.0001)$. No severe adverse effects were observed. Conclusions: These results suggest that ghrelin administration is safe and that this treatment has stimulatory effects on appetite in patients with FD. Further studies are necessary to confirm the efficacy of ghrelin treatment for anorexia-related disorders.
\end{abstract}

European Journal of Endocrinology 158 491-498

\section{Introduction}

Ghrelin is a gut hormone, which is produced mainly in the stomach and a 28-amino acid peptide with an $n$-octanoylation modification at Ser 3 (1). This peptide increases feeding when administered either peripherally or centrally (2-4). Ghrelin is the only hormone that exhibits an orexigenic effect following peripheral administration. The unique action of ghrelin may therefore be invaluable in the development of novel treatments for anorexia-related disorders. In addition, ghrelin exhibits a variety of actions including stimulation of growth hormone $(\mathrm{GH})$ secretion, gastric motility and gastric acid secretion, and induction of positive energy balance $(5,6)$. Preliminary clinical trials have begun to assess the utility of ghrelin for the treatment of cachectic conditions (7-9). Our previous examination of the clinical effects and safety of i.v. lowand high-dose ( 1 and $5 \mu \mathrm{g} / \mathrm{kg}$ respectively) ghrelin in young healthy volunteers demonstrated that ghrelin was safe and tended to increase appetite in a dosedependent manner (10). These findings suggest that ghrelin may be useful for the treatment of disorders related to appetite.

Anorexia is associated with a variety of functional disorders, including functional dyspepsia (FD), eating disorders (EDs), and depression. FD is a disorder characterized by chronic or recurrent symptoms of upper abdominal pain or discomfort (11). Although no specific organic abnormalities are present, abnormalities in gastrointestinal motility and sensitivity are thought to play a role in the dysmotility type of FD, which comprises a substantial subset of patients. Anorexic ED is characterized by chronically decreased caloric intake, resulting in self-induced starvation. Patients with anorexia nervosa (AN), which is a typical anorexic ED, do not eat because of obsession with obesity and/or a distorted body image. Anorexic ED in the absence of obsession with obesity or distorted body image is categorized as 'other EDs' or 'EDs unspecified' 
according to the International Classification of Diseases (ICD)-10 (12). Some patients with FD also suffer from anorexia with body weight loss and are frequently diagnosed with ED. No treatment guidelines for patients with ED and FD have been established. In this study, we investigated whether repeated ghrelin administration could increase appetite and food intake (FI) in patients with functional anorexia.

\section{Subjects and methods}

\section{Patients}

To be included in this study, subjects had to 1) be diagnosed as having FD, as defined by the Rome II criteria (11), and/or categorized as 'other EDs (F50.8)' or 'EDs unspecified (F50.9)' according to the ICD-10 classification (12); 2) be lean $\left(\mathrm{BMI}<22 \mathrm{~kg} / \mathrm{m}^{2}\right)$; and 3) exhibit decreased FI less than the nutritional requirements for Japanese People (13). Exclusion criteria were 1) the presence of organic gastrointestinal disorders, including peptic ulcer disease, erosive gastritis, gastroesophageal reflux disease, or gastric cancer; 2) anorexia due to organic disorders, such as chronic hepatitis, gall bladder stone, chronic pancreatitis, constipation, chronic glomerulonephritis, and chronic heart failure; 3) current usage of prescription proton pump inhibitors and/or antibiotics within 4 weeks of enrolment; 4) classical (F50.0 (12)) or atypical (F50.1 (12)) AN; 5) habitual vomiting; 6) an obsession with obesity or a distorted body image; 7) schizophrenia or severe depression with suicide ideations; 8) systematic autoimmune disease; 9) severe diabetes or cardiac disease; 10) pregnancy; 11) lactation; 12) past history of malignant tumors; and 13) orthostatic hypotension. Medication that had already been started 1 month before the initial enrolment could be continued during this study, unless the drug dose was changed. Within 4 weeks of the initial enrolment and during the entire period of this study, any additional drugs that might influence the study outcome were not allowed, so steroids, analgesics, and antibiotics were not allowed at any period. The initial planned sample size was eight or more. Patient registration lasted from July 2004 to September 2006. The study protocol was approved by the Ethics Committees on Human Research of the Kyoto University Graduate School of Medicine. We obtained written informed consent from all subjects prior to enrolment.

\section{Study design}

Enrolment was performed in two steps (Fig. 1). First, eligible volunteers were enrolled after a 2-week screening period (initial enrolment) and hospitalized for 1 week (from days -7 to -1 ). From days -4 to -2 , daily FIs were measured; subjects whose FI (the mean of three daily FI values) met the inclusion criterion were enrolled on day -1 (final enrolment). These patients received an i.v. infusion of ghrelin $(3 \mu \mathrm{g} / \mathrm{kg}$ ) for $30 \mathrm{~min}$ twice a day (before breakfast and dinner) for 14 days (days 1-14). After treatment, subjects were hospitalized for an additional 1 week (days 15-21) to monitor the safety and clinical efficacy of ghrelin treatment. To establish strict quality control, patient enrolment, monitoring, data management, and statistics were conducted independently and separately.

\section{Study drug}

Human ghrelin was prepared as described previously (10). Acylated peptide was dissolved in 3.75\% D-mannitol to a final concentration of $180 \mu \mathrm{g} / \mathrm{ml}$. Solutions were filtered and stored at $-20{ }^{\circ} \mathrm{C}$ in sterile vials. Examination by the Japan Food Research Laboratories (Tokyo, Japan) did not find any traces of endotoxin in the ghrelin solutions; a pyrogen test based on the Pharmacopoeia of Japan was also negative.

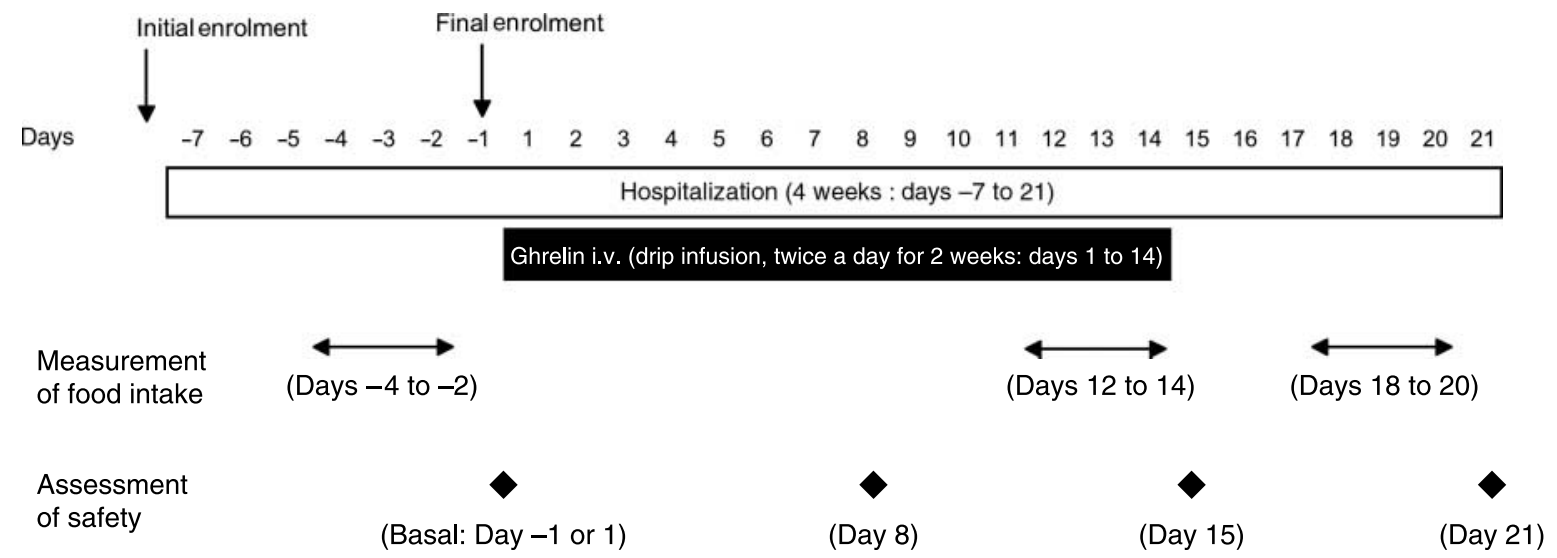

Figure 1 Schematic of the study schedule of enrolment, hospitalization, ghrelin injection, and safety assessment. Day 1 designates the day upon which ghrelin administration was begun. 


\section{Assessment of FI and hunger sensation}

The primary endpoint of this trial was alteration of FI by ghrelin treatment. Patients were initially served an amount of food equivalent to their recommended dietary allowance (58\% carbohydrate, $25 \%$ fat, and $17 \%$ protein). FI was calculated by dieticians as total caloric intake subtracting the residual FI as in calories. When a subject ate all of the food for two consecutive days, the amount of food was increased by $200 \mathrm{kcal} /$ day. If a subject ate a snack or drink, the calories were added to the measurement of FI. The mean daily FI over 3 days was evaluated. Visual analog scales rating hunger (possible scores $0-10 \mathrm{~cm}$ ) were completed pre-infusion and immediately after study drug administration $(10,14,15)$. The positions on the scale were measured in centimeters.

\section{Measurement of hormone, metabolic parameters, and body composition}

Blood samples for the hormone and metabolic parameters were drawn after an overnight fast on days 1,8 , 15, and 21. Plasma levels of active and desacyl ghrelin at the end of injection were also measured to confirm the increases using ELISA kits (Mitsubishi Kagaku Iatron Inc., Tokyo, Japan). GH (normal values: male, $<1.46$; female, $0.28-8.70 \mathrm{ng} / \mathrm{ml}$ ) and insulin-like growth factor-I (IGF-I) were measured by IRMA (Mitsubishi Kagaku Bio-Clinical Laboratories Inc., Tokyo, Japan). Body composition was determined using dual energy X-ray absorptiometry (DEXA, QDR2000; Hologic Inc., Waltham, MA, USA).

\section{Assessment of safety}

Vital signs, including blood pressure, pulse rate, and body temperature, were measured every day. Assessments of safety by hematology, blood chemistry, and urine analysis were performed on days 1, 8, 15, and 21 . Anxiety levels were evaluated using the Japanese versions of the Self-Rating Anxiety Scale (SAS) (16) and the State-Trait Anxiety Inventory (STAI) (17) tests on days $-1,8,15$, and 21 . If the study was interrupted, evaluation was performed when the study was discontinued.

\section{Statistical evaluations}

A sample size of eight will have $95 \%$ power to detect a difference in means of $-300 \mathrm{kcal}$, i.e., expected relative improvement of $25 \%$ (4) (e.g., a baseline mean of $1200 \mathrm{kcal}$ and a post-treatment mean of $1500 \mathrm{kcal}$ ), assuming a standard deviation of differences of $200 \mathrm{kcal}$, using a paired $t$-test with a 0.05 two-sided significance level. Statistical analyses were performed using SAS version 8 software (SAS Institute Inc., Cary,
NC, USA). A two-tailed $P$ value was used, with the required level of significance being set at 0.05.

\section{Results \\ Baseline characteristics of subjects}

Six subjects, three men and three women, were enrolled in this study (Table 1). Although the initial planned sample size was eight or more, enrolment was finished at six because of the end of study term and the difficulties with enrolment. All six subjects were diagnosed with FD (Table 1). Patients 5 and 6 also exhibited mild depression and panic disorder respectively. BMI and FI (\% of recommended daily allowance) at final registration were $17.6 \pm 1.9 \mathrm{~kg} / \mathrm{m}^{2}$ and $63.2 \pm$ $17.4 \%$ (mean \pm s.D.) respectively. Plasma levels of active and desacyl ghrelin appeared to be within normal limits, considering BMI levels and ages (18). Four patients completed the 3-week ghrelin injection course. One patient (patient 5) was dismissed after the final injection and cancelled the examination 1-week postinjection. The last patient (patient 6) discontinued the ghrelin injections on day 6 because he could not continue to be hospitalized.

\section{Clinical effects}

Plasma levels of active and desacyl ghrelin at the end of injection at day 1 were $3211 \pm 332$ (pre-injection: $17.1 \pm 10.9$ ) and $993 \pm 193.1$ (pre-injection: $96.9 \pm$ 29.2) $\mathrm{fmol} / \mathrm{ml}$ respectively. Ghrelin injection tended to increase daily FI in comparison with levels seen before (days -4 to -2) and after treatment (days 12-14), although this difference was not statistically significant $(P=0.084$; Table 2; Fig. 2A). The statistical power of the study to detect the observed difference (the baseline mean of $1255.9 \mathrm{kcal}$, the post-treatment mean of $1619.8 \mathrm{kcal}$ and the standard deviation of difference of $355.1 \mathrm{kcal}$ ) based on five subjects was $41 \%$. The increase in FI was observed for all three meals (breakfast, lunch, and dinner), but was most pronounced at dinner $(P=0.0504)$. The elevated FI appeared to be maintained even 1 week after treatment (days 18-20; Fig. 2A). In individuals, FI increased in four of five subjects, while it decreased in patient 5 (Fig. 2B). FI in patient 1 was significantly elevated at the end of ghrelin treatment (days 12-14) from levels observed before treatment $(P<0.005)$. In patients 2 and 4 , amounts of food were increased by $200 \mathrm{kcal} /$ day at days 9 and 12 respectively, because they ate all of the food for the previous 2 days.

Ghrelin administration significantly increased the hunger sensation experienced at the end of drip infusion $(N=149, P<0.0001$; Fig. 3A). This effect was observed at similar levels during both morning $(N=75$, $P<0.0001)$ and evening $(N=74, P=0.0002)$. 


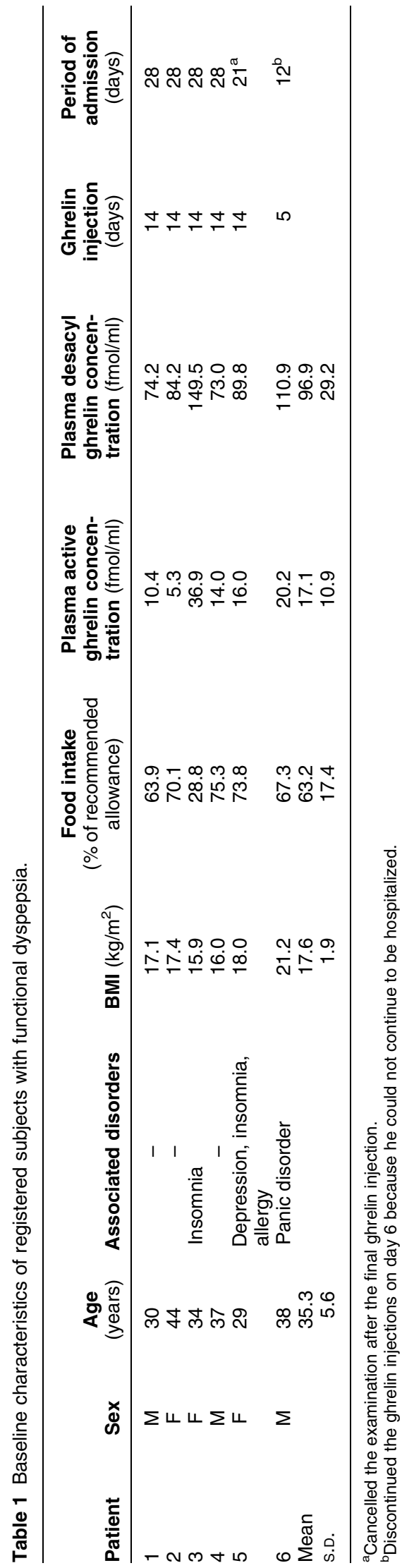

Individually, three of the subjects exhibited significantly increased appetites after treatment, whereas the remaining patients did not (Fig. 3B). Interestingly, the former group demonstrated higher hunger scores before treatment than the latter group.

Patient body weight did not significantly change after treatment. At the end of treatment, basal serum GH and IGF levels tended to have decreased $(P=0.080)$ and increased $(P=0.090)$ respectively, but returned to baseline levels within 1 week (Table 2). Lean body mass tended to increase, while fat mass tended to decrease after treatment (Table 2). There were no significant changes in the blood levels of other hormones or other metabolic parameters, including serum insulin, glucose, adrenocorticotrophin (ACTH), cortisol, thyrotrophin (TSH), free thyroxine, free tri-iodothyronine, prolactin, luteinizing hormone, follicle-stimulating hormone, estrogen, testosterone, glucagon, leptin, albumin, and cholinesterase following ghrelin treatment.

\section{Adverse effects}

No serious adverse events were reported. We observed 36 mild and 4 moderate events. Of these, 11 events, all of which were mild, were considered to be associated with ghrelin treatment. These incidences were similar to those that had been previously reported, with eight abdominal events (peristalsis, hunger, discomfort, and pain) and one event each of flushing, somnolence, and hyperhidrosis. All of these complaints were transient and well tolerated. We could not detect any changes in clinical blood chemistries or complete blood counts after ghrelin treatment. Anxiety levels that were evaluated by the SAS and STAI tests did not significantly change with ghrelin treatment. We did not observe any significant effects of ghrelin treatment on sleep or basal levels (pre-infusion) of heart rate and blood pressure.

\section{Discussion}

In this study, $3 \mu \mathrm{g} / \mathrm{kg}$ ghrelin was intravenously injected twice a day for 14 days. Although several studies demonstrated that a single injection of $1 \mu \mathrm{g} / \mathrm{kg}$ ghrelin caused hunger sensation in some healthy subjects (19, $20)$, we observed that ghrelin tended to increase appetite dose dependently (1 vs $5 \mu \mathrm{g} / \mathrm{kg}$ ) in a phase I study and was safe at the dose of $5 \mu \mathrm{g} / \mathrm{kg}$ (10). In addition, an i.v. injection of ghrelin twice a day (morning and evening) for 3 weeks to patients with congestive heart failure increased both FI and body weight (7). Furthermore, once a day injection of ghrelin tended to increase energy intake for the rest of the days and/or total $24 \mathrm{~h}(4,8)$. Based on these findings, we adopted the present protocol.

Although ghrelin injection significantly increased appetite and tended to increase daily FI in comparison 
Table 2 Summary of clinical effects of ghrelin treatment.

\begin{tabular}{|c|c|c|c|c|c|c|c|c|c|c|c|c|c|}
\hline & \multicolumn{4}{|c|}{ Before treatment } & \multicolumn{5}{|c|}{ At the end of treatment } & \multicolumn{4}{|c|}{ One week after treatment } \\
\hline & Day(s) & $N^{\mathrm{a}}$ & Mean & S.D. & Day(s) & $N^{\mathrm{a}}$ & Mean & S.D. & $P$ value ${ }^{b}$ & Day(s) & $N^{\mathrm{a}}$ & Mean & S.D. \\
\hline \multirow[t]{2}{*}{ Food intake (kcal/day) } & -4 to -2 & $\begin{array}{l}6 \\
5\end{array}$ & $\begin{array}{l}1326.9 \\
1255.9\end{array}$ & $\begin{array}{l}493.8 \\
516.7\end{array}$ & $12-14$ & 5 & 1619.8 & 703.1 & 0.084 & 18 to 20 & & & \\
\hline & & 4 & 1265.5 & 596.2 & & 4 & 1754.3 & 733.8 & & & 4 & 1692.0 & 815.4 \\
\hline \multirow[t]{2}{*}{ Weight (kg) } & -1 & $\begin{array}{l}6 \\
5\end{array}$ & $\begin{array}{l}48.3 \\
45.5\end{array}$ & $\begin{array}{l}9.0 \\
6.7\end{array}$ & 15 & 5 & 45.7 & 6.7 & 0.339 & 21 & & & \\
\hline & & 4 & 45.0 & 7.6 & & 4 & 45.3 & 7.7 & & & 4 & 45.1 & 7.2 \\
\hline \multirow{3}{*}{ Serum GH (ng/ml) } & 1 & 6 & 0.41 & 0.37 & 14 & & & & & 21 & & & \\
\hline & & 5 & 0.48 & 0.37 & & 5 & 0.12 & 0.04 & 0.080 & & & 0.16 & 0.05 \\
\hline & & 4 & 0.35 & 0.27 & & 4 & 0.10 & 0.02 & & & 4 & & \\
\hline \multirow{3}{*}{ Serum IGF-I (ng/ml) } & 1 & 6 & 193.8 & 53.4 & 15 & & & & & 21 & & & \\
\hline & & 5 & 182.5 & 51.1 & & 5 & 225.7 & 92.0 & 0.090 & & & & \\
\hline & & 4 & 171.9 & 52.3 & & 4 & 207.6 & 94.8 & & & 4 & 208.5 & 84.1 \\
\hline \multirow[t]{3}{*}{ Lean body mass (\%) } & -5 to -1 & 6 & 78.8 & 6.6 & $14-16$ & & & & & n.d. & & & \\
\hline & & 5 & 78.4 & 7.3 & & 5 & 79.3 & 7.9 & 0.131 & & & & \\
\hline & & 4 & 80.4 & 6.8 & & 4 & 81.6 & 6.9 & & & & & \\
\hline \multirow[t]{3}{*}{ Fat mass (\%) } & -5 to -1 & $\begin{array}{l}4 \\
6\end{array}$ & 16.9 & 6.8 & $14-16$ & & & & & n.d. & & & \\
\hline & & 5 & 17.5 & 7.4 & & 5 & 16.7 & 8.0 & 0.170 & & & & \\
\hline & & 4 & 15.6 & 7.0 & & 4 & 14.4 & 7.1 & & & & & \\
\hline \multirow[t]{3}{*}{ Serum glucose (mg/dl) } & 1 & 6 & 80.7 & 10.4 & 15 & & & & & 21 & & & \\
\hline & & 5 & 84.2 & 6.5 & & 5 & 82.8 & 4.6 & 0.669 & & & & \\
\hline & & 4 & 85.8 & 6.4 & & 4 & 82.8 & 5.3 & & & 4 & 78.0 & 7.7 \\
\hline \multirow[t]{3}{*}{ Serum insulin $(\mu \mathrm{U} / \mathrm{ml})$} & 1 & 6 & 4.7 & 2.9 & 15 & & & & & 21 & & & \\
\hline & & 5 & 5.2 & 2.9 & & 5 & 4.1 & 0.9 & 0.502 & & & & \\
\hline & & 4 & 5.1 & 3.3 & & 4 & 4.2 & 1.0 & & & 4 & 4.7 & 2.9 \\
\hline \multirow{3}{*}{$\begin{array}{l}\text { Plasma active ghrelin } \\
\text { concentration }(\mathrm{fmol} / \mathrm{ml})\end{array}$} & 1 & 6 & 17.1 & 10.9 & 15 & & & & & 21 & & & \\
\hline & & 5 & 16.5 & 12.1 & & 5 & 16.5 & 8.8 & 0.985 & & & & \\
\hline & & 4 & 16.7 & 14.0 & & 4 & 15.8 & 10.0 & & & 4 & 11.8 & 5.2 \\
\hline \multirow{3}{*}{$\begin{array}{l}\text { Plasma desacyl ghrelin } \\
\text { concentration (fmol/ml) }\end{array}$} & 1 & 6 & 96.9 & 29.2 & 15 & & & & & 21 & & & \\
\hline & & 5 & 94.1 & 31.7 & & 5 & 85.4 & 37.7 & 0.463 & & & & \\
\hline & & 4 & 95.2 & 36.5 & & 4 & 85.6 & 43.5 & & & 4 & 77.5 & 46.3 \\
\hline \multicolumn{14}{|c|}{$\begin{array}{l}\text { n.d., not done. } \\
\text { a } N=6 \text {, all patients; } N=5 \text {, excluding patient } 6 ; N=4 \text {, excluding patients } 5 \text { and } 6 \text {. } \\
\text { bPaired } t \text {-test versus levels before treatment. }\end{array}$} \\
\hline
\end{tabular}



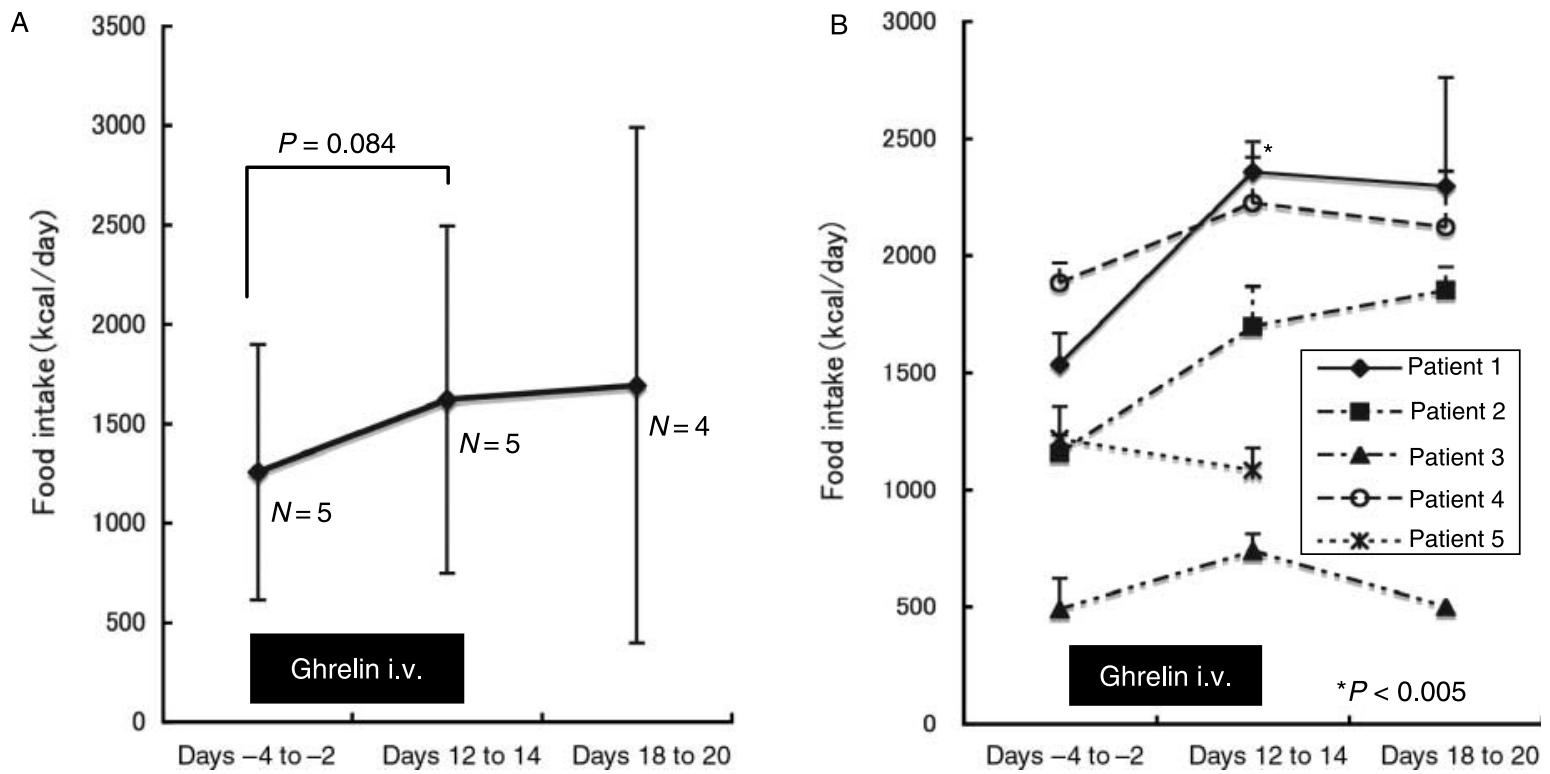

Figure 2 Daily FI was measured before ghrelin injection (days -4 to -2 ), at the completion of treatment (days 12-14), and 1 week after injection (days 18-20) in five subjects who completed 2 weeks of ghrelin treatment. (A) Mean and 95\% confidence interval (Cl) for five subjects. (B) Three-day means and standard deviation of daily FI for each subject.

with levels seen before and after treatment (Table 2; Fig. 2A), the difference in FI did not reach statistical significance $(P=0.084)$. This may be due to the small number of subjects included in this study. The number of subjects enrolled was six and one of them did not complete ghrelin injections. Indeed, the statistical power of this study was calculated as only $41 \%$. In addition, the study group is heterogeneous as two patients had comorbidity with psychiatric disorders, although all subjects were diagnosed with FD. These factors might have made this study underpowered. Obviously, further studies using more subjects are needed to confirm the effects of ghrelin on FI in these patients.

FI increased in four of five subjects after ghrelin treatment, while it decreased in patient 5 (Fig. 2B). The significant increase in appetite after treatment was observed in three patients but not others, although ghrelin injection significantly increased appetite in the whole (Fig. 3). These findings suggest that the effects of ghrelin on FI and appetite differ among individuals. It is
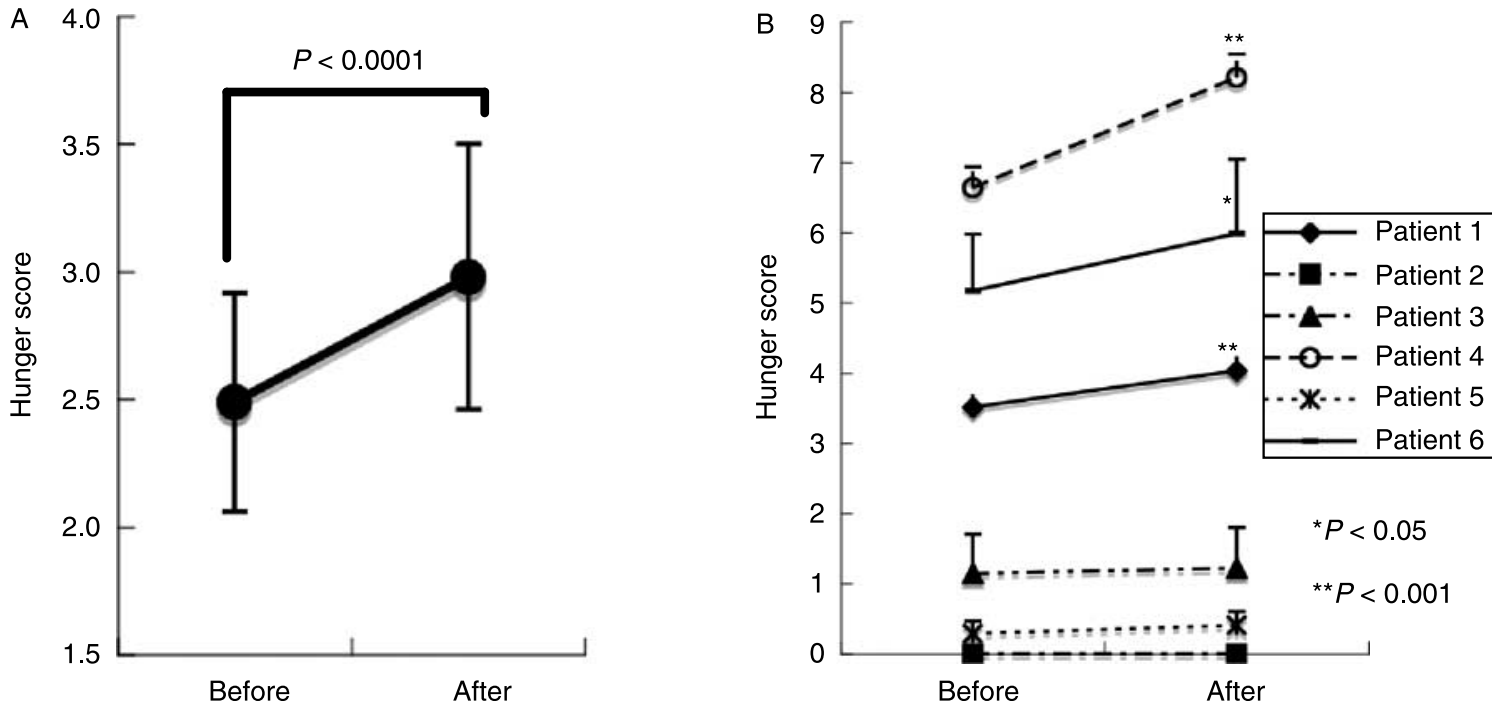

Figure 3 Effect of ghrelin injection on appetite as measured by the VAS hunger score before and after ghrelin injection. The mean and $95 \%$ $\mathrm{Cl}$ for $(\mathrm{A})$ all six subjects $(N=149)$ and $(\mathrm{B})$ for each subject $(N=28$ except for patient $6(N=9))$ are shown. 
unclear why ghrelin did not increase FI in patient 5; this patient also exhibited depression, with high anxiety scores on both the STAI (STAI-state, 75-80 vs 27-47 points for other subjects; STAI-trait, 77-80 vs 29-54 points for other subjects) and SAS (49-55 vs 26-55 points for other subjects) tests throughout the trial. In this patient, ghrelin may have been unable to overcome the anorexia associated with severe anxiety/depression or complex etiology. Further study is needed to better understand these varying responses observed. Interestingly, alterations of appetite did not always parallel changes in FI. The FI of patients 2 and 3 tended to be increased, while their hunger scores did not change (Figs 2B and 3B), suggesting that FI is influenced by mechanisms independent from appetite.

FI tended to remain elevated after completion of ghrelin treatment (days 18-20) in some patients, e.g., patients 1 and 4 . Because the reduction of their body weights was not observed at day 15 , it is unlikely that acute weight loss caused the persistent elevation of FI in these subjects after cessation of ghrelin treatment. Although the precise mechanism is not known, several possibilities exist. First, acute effects of ghrelin on gastric function may lead to sequential favorable events in gastric mucosa and/or function. Secondly, the improvement in FI may result from an improvement in anxiety concerning FI or a gain of confidence in these patients. Thus, the effect of ghrelin may persist even after the cessation of treatment.

FD is related to disordered gastric emptying, dysregulation of gastroduodenal motility, and visceral hypersensitivity. As ghrelin affects gastric motility and secretion $(21,22)$, this peptide may affect FI by influencing gastric emptying and motility in patients with FD. A subset of subjects exhibited increased FI after treatment, despite minimal changes in appetite. Conversely, the functional abnormalities in FD may affect the production of ghrelin in the stomach. Plasma ghrelin levels have been reported to be altered (23, 24) and/or correlate with FD symptom score $(24,25)$. Further studies are necessary to determine the pathophysiological role of ghrelin in FD.

Serum IGF levels tended to increase by the end of treatment, although these changes were not statistically significant. Ghrelin treatment likely stimulates $\mathrm{GH}$ secretion $(1,26)$. The subsequent decrease in basal $\mathrm{GH}$ levels may reflect negative feedback from the elevated IGF-I. IGF-I and GH exhibit muscle-enhancing and lipolytic actions respectively, which are compatible with the trend of increased lean body mass and decreased fat mass seen in our patients after treatment. We did not observe any additional changes in serum hormone levels or other metabolic parameters indicative of glucose metabolism, the ACTH-adrenal axis, the TSH-thyroid axis, prolactin, or the gonadotropingonadal axis, suggesting that ghrelin minimally affects these systems under these conditions.
No severe adverse effects were observed. All complaints, including mild abdominal discomfort, flushing, perspiration, and somnolence, were transient and well tolerated. Ghrelin did not significantly alter clinical blood chemistries, complete blood counts, and anxiety scores. Thus, ghrelin treatment appears to be safe.

In summary, this is the first report examining the efficacy of ghrelin in the treatment of conditions with functional anorexia, including FD. Although the increase in FI did not reach statistical significance, alterations in appetite and FI seen after treatment appeared to support the therapeutic potential of ghrelin in patients with such disorders. We also confirmed ghrelin's safety. Further studies including placebocontrolled larger ones are awaited to confirm the usefulness of ghrelin in the treatment of FD.

\section{Acknowledgements}

We thank Dr Hashida for preparing the drugs used in this study and Drs Ichiyama, Hayashi, Chusho, Tagami, Shimatsu, Onaka, Tominaga, and Hosokawa for patient consultations. We would also like to thank Ms Kouchi, Nakatani, and Amemiya for their excellent secretarial assistance. This study was supported by funds from the Ministry of Education, Science, Culture, Sports and Technology of Japan. The FD Clinical Study Team includes the following individuals: T Irako, H Tada, I Bando, K Miura, A Matsuyama, A Shimizu, M Fukushima, K Shide, Y Tamai, N Watanabe, and H Nakase at Kyoto University Hospital, T Abe and T Shinomiya at Kansai Medical University, A Fukao at Otowa Hospital, and M Suda at Kyoto Municipal Hospital.

\section{References}

1 Kojima M, Hosoda H, Date $Y$, Nakazato M, Matsuo H \& Kangawa K. Ghrelin is a growth-hormone-releasing acylated peptide from stomach. Nature $1999 \mathbf{4 0 2} 656-660$.

2 Tschop M, Smiley DL \& Heiman ML. Ghrelin induces adiposity in rodents. Nature $2000 \mathbf{4 0 7} 908-913$.

3 Wren AM, Small CJ, Ward HL, Murphy KG, Dakin CL, Taheri S, Kennedy AR, Roberts GH, Morgan DG, Ghatei MA \& Bloom SR. The novel hypothalamic peptide ghrelin stimulates food intake and growth hormone secretion. Endocrinology $20001414325-4328$.

4 Wren AM, Seal LJ, Cohen MA, Brynes AE, Frost GS, Murphy KG, Dhillo WS, Ghatei MA \& Bloom SR. Ghrelin enhances appetite and increases food intake in humans. Journal of Clinical Endocrinology and Metabolism $2001 \mathbf{8 6} 5992$.

5 van der Lely AJ, Tschop M, Heiman ML \& Ghigo E. Biological, physiological, pathophysiological, and pharmacological aspects of ghrelin. Endocrine Reviews 200425 426-457.

6 Korbonits M, Goldstone AP, Gueorguiev M \& Grossman AB. Ghrelin - a hormone with multiple functions. Frontiers in Neuroendocrinology 200425 27-68.

7 Nagaya N, Moriya J, Yasumura Y, Uematsu M, Ono F, Shimizu W, Ueno K, Kitakaze M, Miyatake K \& Kangawa K. Effects of ghrelin administration on left ventricular function, exercise capacity, and muscle wasting in patients with chronic heart failure. Circulation $20041103674-3679$. 
8 Neary NM, Small CJ, Wren AM, Lee JL, Druce MR, Palmieri C, Frost GS, Ghatei MA, Coombes RC \& Bloom SR. Ghrelin increases energy intake in cancer patients with impaired appetite: acute, randomized, placebo-controlled trial. Journal of Clinical Endocrinology and Metabolism $2004892832-2836$.

9 Nagaya N, Itoh T, Murakami S, Oya H, Uematsu M, Miyatake K \& Kangawa K. Treatment of cachexia with ghrelin in patients with COPD. Chest $2005 \mathbf{1 2 8} 1187-1193$.

10 Akamizu T, Takaya K, Irako T, Hosoda H, Teramukai S, Matsuyama A, Tada H, Miura K, Shimizu A, Fukushima M, Yokode M, Tanaka K \& Kangawa K. Pharmacokinetics, safety, and endocrine and appetite effects of ghrelin administration in young healthy subjects. European Journal of Endocrinology $2004 \mathbf{1 5 0}$ 447-455.

11 Talley NJ, Stanghellini V, Heading RC, Koch KL, Malagelada JR \& Tytgat GN. Functional gastroduodenal disorders. Gut $1999 \mathbf{4 5}$ (Suppl 2) II37-II42.

12 World Health Organization. Chapter V. Mental and behavioural disorders. In International Statistical Classification of Diseases and Related Health Problems 10th Revision. Geneva: WHO, 1992.

13 Health promotion and Nutrition division, Health service bureau \& Ministry of Health and Welfare of Japan. Recommended Dietary Allowances for the Japanese-5th Revision. Tokyo: Dai-ichi Shuppan, 1996.

14 Thompson DA \& Campbell RG. Hunger in humans induced by 2-deoxy-D-glucose: glucoprivic control of taste preference and food intake. Science $1977 \mathbf{1 9 8} 1065-1068$.

15 Nakai Y, Kinoshita F, Koh T, Tsujii S \& Tsukada T. Perception of hunger and satiety induced by 2-deoxy-D-glucose in anorexia nervosa and bulimia neervosa. International Journal of Eating Disorders 19876 49-57.

16 Zung WW. A rating instrument for anxiety disorders. Psychosomatics $197112371-379$.

17 Iwata N, Mishima N, Shimizu T, Mizoue T, Fukuhara M, Hidano T \& Spielberger CD. The Japanese adaptation of the STAI Form Y in Japanese working adults - the presence or absence of anxiety. Industrial Health 199836 8-13.

18 Akamizu T, Shinomiya T, Irako T, Fukunaga M, Nakai Y \& Kangawa K. Separate measurement of plasma levels of acylated and desacyl ghrelin in healthy subjects using a new direct ELISA assay. Journal of Clinical Endocrinology and Metabolism 200490 6-9.

19 Arvat E, Di Vito L, Broglio F, Papotti M, Muccioli G, Dieguez C, Casanueva FF, Deghenghi R, Camanni F \& Ghigo E. Preliminary evidence that Ghrelin, the natural GH secretagogue (GHS)receptor ligand, strongly stimulates $\mathrm{GH}$ secretion in humans. Journal of Endocrinological Investigation 200023 493-495.

20 Broglio F, Arvat E, Benso A, Gottero C, Muccioli G, Papotti M, van der Lely AJ, Deghenghi R \& Ghigo E. Ghrelin, a natural GH secretagogue produced by the stomach, induces hyperglycemia and reduces insulin secretion in humans. Journal of Clinical Endocrinology and Metabolism 200186 5083-5086.

21 Masuda Y, Tanaka T, Inomata N, Ohnuma N, Tanaka S, Itoh Z, Hosoda H, Kojima M \& Kangawa K. Ghrelin stimulates gastric acid secretion and motility in rats. Biochemical and Biophysical Research Communications $2000 \mathbf{2 7 6} 905-908$.

22 Mori M, Suzuki H, Masaoka T, Imaeda H, Nomoto Y, Hosoda H, Nishizawa T, Kangawa K \& Hibi T. Intravenous ghrelin administration enhances gastric acid secretion - evaluation using wireless $\mathrm{pH}$ capsule. Alimentary Pharmacology $\mathcal{E}$ Therapeutics 200624 (Suppl 4) 96-103.

23 Takamori K, Mizuta Y, Takeshima F, Akazawa Y, Isomoto H, Ohnita K, Ohba K, Omagari K, Shikuwa S \& Kohno S. Relation among plasma ghrelin level, gastric emptying, and psychologic condition in patients with functional dyspepsia. Journal of Clinical Gastroenterology 200741 477-483.

24 Nishizawa T, Suzuki H, Nomoto Y, Masaoka T, Hosoda H, Mori M, Ohara T, Morishita T, Kangawa K \& Hibi T. Enhanced plasma ghrelin levels in patients with functional dyspepsia. Alimentary Pharmacology \& Therapeutics 200624 (Suppl 4) 104-110.

25 Shinomiya T, Fukunaga M, Akamizu T, Irako T, Yokode M, Kangawa K, Nakai Y \& Nakai Y. Plasma acylated ghrelin levels correlate with subjective symptoms of functional dyspepsia in female patients. Scandinavian Journal of Gastroenterology $2005 \mathbf{4 0}$ 648-653.

26 Takaya K, Ariyasu H, Kanamoto N, Iwakura H, Yoshimoto A, Harada M, Mori K, Komatsu Y, Usui T, Shimatsu A, Ogawa Y, Hosoda K, Akamizu T, Kojima M, Kangawa K \& Nakao K. Ghrelin strongly stimulates growth hormone release in humans. Journal of Clinical Endocrinology and Metabolism 200085 4908-4911.

Received 17 December 2007

Accepted 3 January 2008 